\title{
Activation routes for high surface-area graphene monoliths from graphene oxide colloids
}

Shuwen Wang ${ }^{a, 1}$, Ferdinando Tristan ${ }^{a, 2}$, Daiki Minami ${ }^{a, 1}$, Toshihiko Fujimori ${ }^{a, 1}$, Rodolfo Cruz-Silva ${ }^{a, 3}$, Mauricio Terrones ${ }^{a, 4}$, Kenji Takeuchi ${ }^{b}$, Katsuya Teshima ${ }^{b}$, Francisco Rodríguez-Reinoso ${ }^{c}$, Morinobu Endo ${ }^{a, 3}$, and Katsumi Kaneko ${ }^{a, 1} *$

a. Research Center for Exotic Nanocarbons (JST), Shinshu University, Wakasato, Nagano, 380-8553, Japan

b. Faculty of Engineering, Shinshu University, Wakasato, Nagano, 380-8553, Japan

c. Department of Inorganic Chemistry, University of Alicante, Apartado 99, E-03080 Alicante, Spain

1. Present address: Center for Energy and Environmental Science, Shinshu University, Wakasato, Nagano, 380-8553, Japan

2. Present address: Faculty of Natural Science, Universidad Nacional Autonoma de Mexico, Deleg Alvaro Obregon, 01120, Mexico

3. Present address: Center for Acqua Innovation, Shinshu University, Wakasato, Nagano, 380-8553, Japan

4. Present address: Department of Physics, Pennsylvania State University, University Park, PA 16802, USA

*To whom correspondence should be addressed. E-mail: kkaneko@shinshu-u.ac.jp Tel: +81-(0)26-269-5743 Fax: +81-(0)26-269-5737

Abstract: Monoliths made from graphene oxide colloids by unidirectional freeze-drying method were activated by typical activation processes of $\mathrm{CO}_{2}$ activation, chemical activation using $\mathrm{ZnCl}_{2}$ or $\mathrm{H}_{3} \mathrm{PO}_{4}$, and $\mathrm{KOH}$ activation. The porosity development of graphene monolith markedly depends on the activation method. The monoliths with highest surface area are obtained by the $\mathrm{KOH}$ activation method; only the $\mathrm{KOH}$ activation was effective for production of the graphene monolith of which surface area was in the range of 1760 to 2150 $\mathrm{m}^{2} \mathrm{~g}^{-1}$. The mechanism of the porosity development by $\mathrm{KOH}$ activation method is proposed. 
This work provides a promising route for the bottom-up design of pore width-tunable nanoporous carbons.

\section{Introduction}

Nanoporous carbon of high surface area has contributed to environmental, energy, and chemical technologies [1-5]. This is because nanoporous carbons have distinguished merits such as high electrical and thermal conductivities [6,7], excellent water resistivity [8], and considerably high chemical stability except for that in an oxidative atmosphere, although the tunability of pore width is not sufficiently established yet. The high electrical and thermal conductivities are superior to other nanoporous materials such as zeolites and metal organic frameworks (MOFs). Also nanoporous carbon has the strongest interaction potential for molecules per unit weight [9]. Furthermore, it has another merit of slit-shaped pores which enable to guarantee excellent accessibility for molecules and ions, being indispensable to industrial applications [10]. The high accessibility of the slit-shaped pores is essentially important, because the pre-adsorbed molecules near the pore entrance of the cylindrical pores often intervene the intrapore diffusion [11].

The most serious issue of nanoporous carbons is ill-tunability of the pore width. Recently developed carbide-derived carbon has a considerably high tunability of the pore width [12-14]. The tunability, however, is inferior to that of zeolites with ion-exchange and of MOFs with changing ligands and metal ions. One promising route for a better pore width-tunability of nanoporous carbons is on the bottom-up designing using graphene chemistry. In particular, the bottom-up synthesis of graphene-based nanoporous carbons using graphene oxide colloids (GOCs) is the most promising. However, no systematic study on the 
bottom-up designing using GOCs has been reported, although the effectiveness of $\mathrm{KOH}$-activation was shown for production of the high surface area graphene with relevance to supercapacitors [3]. This article describes effectiveness of different activation processes for GOCs derived carbon, which have been applied to production of traditional activated carbons. In this study, we investigated three typical activation processes of $\mathrm{CO}_{2}$ activation, chemical activation using $\mathrm{ZnCl}_{2}$ or $\mathrm{H}_{3} \mathrm{PO}_{4}$, and $\mathrm{KOH}$ activation.

\section{Experimental}

\subsection{Graphene oxide colloid (GOC) preparation}

GOCs were prepared from natural graphite (Bay carbon graphite from Michigan, USA and Madagascar graphite from Madagascar) by an improved method using $\mathrm{KMnO}_{4}, \mathrm{H}_{2} \mathrm{SO}_{4}$ and $\mathrm{H}_{3} \mathrm{PO}_{4}$ [15]. In the preparation process, concentrated $\mathrm{H}_{2} \mathrm{SO}_{4}\left(96 \%, 200 \mathrm{~mL}\right.$, Wako), $\mathrm{H}_{3} \mathrm{PO}_{4}$ (85\%, $25 \mathrm{~mL}$, Wako) and graphite (5 g) were added into a beaker, followed by a slow addition of $\mathrm{KMnO}_{4}(25 \mathrm{~g}$, Wako). The mixture was then kept at 308-313 $\mathrm{K}$ and stirred at 250 rpm for $2 \mathrm{~h}$. After the reaction, $500 \mathrm{~mL}$ distilled water was added slowly into the mixture followed by a $10 \% \mathrm{H}_{2} \mathrm{O}_{2}$ solution $(100 \mathrm{~mL})$. The oxidation product was then washed by $1 \mathrm{M}$ $\mathrm{HCl}$ and distilled water respectively, followed by a centrifugation step to remove the supernatant. It is noticed that in the acid washing process, the oxidation product was highly condensed and occupied a small volume in the centrifuge tubes after centrifugation, thus the liquid residue was small and the metal ion removal was efficient. During the water washing process the oxidation product started to exfoliate and occupied a much larger volume, which retained a larger amount of liquid residue thus the metal ion removal became less effective. In this article, graphene oxide (GO) after single acid washing is named as GO-I (impure GO), 
while that after 5 times acid washing is named as GO-P (highly pure GO), when the classification is necessary; only GO-P was used in the absence of the classification. After the acid washing, both of GO-I and GO-P were further washed five times with distilled water.

\subsection{Preparation of highly porous reduced GO monoliths}

The GO monoliths were produced with unidirectional freeze drying method used for production of other materials [16-20]. The obtained monoliths were heated up to $573 \mathrm{~K}$ at a rate of $1.5 \mathrm{~K} \mathrm{~min}^{-1}$ and then the reduced GO (RGO) monoliths were obtained. The RGO from impure graphene oxide is nominated as RGO-I, and that from highly pure graphene oxide is nominated as RGO-P. It is noticed that the property of GO suspensions produced from different graphites are very different from each other. After the oxidation process, the GO derived from Madagascar graphite is easy to exfoliate in water to form a larger volume of GO suspension. Besides, the GO suspension produced by this way is highly viscous, so that it's very difficult to get highly condensed GO suspension even after an intensive of centrifugation; the produced monoliths have a relatively lower carbon density, being unsuitable for an efficient activation process. On the other hand, GO suspension produced from Bay carbon graphite is less viscous and forms the highly concentrated precipitates after the intensive centrifugation. However, thus produced monoliths are too weak to maintain a constant shape. To compromise this problem, we produced the RGO monoliths from the mixture of these two kinds of GO suspensions at the carbon mole ratio of Bay carbon graphite to Madagascar graphite of 2 to 1 .

The RGO monoliths were activated as follows. The monolith was heated under a flow of pure $\operatorname{Ar}\left(200 \mathrm{~mL} \mathrm{~min}^{-1}\right)$ from room temperature to target temperature at a heating rate of $10 \mathrm{~K}$ 
$\min ^{-1}$. The activation was carried out by feeding $30 \% \mathrm{CO}_{2}$ diluted with Ar at a total flow rate of $200 \mathrm{~mL} \mathrm{~min}^{-1}$, with varying activation time and temperature. Subsequently, the sample was purged by pure Ar during cooling down to room temperature. Activation using chemical reagents like $\mathrm{ZnCl}_{2}, \mathrm{H}_{3} \mathrm{PO}_{4}$, and $\mathrm{KOH}$ was carried out by a one-step activation method. Before the preparation of GO monoliths, the chemical reagents were mixed with GO-P suspensions in advance, then the reduced GO monoliths were produced from the mixtures using the unidirectional freeze drying method followed by reduction method as mentioned above. The GO monoliths prepared with chemical reagents shrank after the freeze drying process, due to the aggregation of GO colloids on addition of the chemical reagents. This is because addition of the chemical reagent into the colloids removes the effective charges of the GO colloids by adsorption of ions having opposite charges, resulting in the aggregation. The obtained monoliths were heated from room temperature to $573 \mathrm{~K}$ at a heating rate of 1.5 $\mathrm{K} \min ^{-1}$, then from $573 \mathrm{~K}$ to target temperatures at a heating rate of $30 \mathrm{~K} \mathrm{~min}^{-1}$. Then the samples were kept at the target temperature for $1 \mathrm{~h}$ before cooling down to room temperature. The system was purged with an Ar flow of $400 \mathrm{~mL} \mathrm{~min}^{-1}$ during the whole process. The products were dipped in distilled water for $4 \mathrm{~h}$ and then such washing was repeated 4 times. After the fourth washing the electric resistance of the supernatant was $(1.3 \pm 0.1) \times 10^{6} \Omega \mathrm{cm}$, being close to $(1.5 \pm 0.1) \times 10^{6} \Omega \mathrm{cm}$ of the used distilled water. Finally the products were dried at $393 \mathrm{~K}$ for $24 \mathrm{~h}$. The activated RGO is named as A-RGO.

\subsection{Characterization methods}

Electronic states of $\mathrm{C}_{1 \mathrm{~s}}$ of as-prepared GO monolith, GO monoliths reduced at $573 \mathrm{~K}$ and $873 \mathrm{~K}$, and RGO monolith activated by $\mathrm{KOH}$ were examined by X-ray photoelectron 
spectroscopy (XPS: JEOL JPS-9010MX, Japan) with Mg Ka radiation; the applied voltage and current were $10 \mathrm{kV}$ and $10 \mathrm{~mA}$, respectively. The reduction state of the GO monolith was also examined by qualitative electrical resistance measurement of the monolith using two point-electrodes method at the inter-electrode distance of $5 \mathrm{~cm}$. Porosity analysis was performed by $\mathrm{N}_{2}$ adsorption at $77 \mathrm{~K}$ with a Micromeritics ASAP 2020 surface analyzer. The samples were pre-evacuated at $473 \mathrm{~K}$ for $3 \mathrm{~h}$ before $\mathrm{N}_{2}$ adsorption. The total surface area and external surface area were determined by the subtracting pore effect (SPE) method using high resolution $\alpha_{\mathrm{s}}$-plot of the $\mathrm{N}_{2}$ adsorption isotherm [21, 22]. The surface area was also determined according to the Brunauer-Emmett-Teller (BET) method in a relative pressure range of $0.05-0.30$ for comparison, although the BET analysis gives an overestimated surface area. The linear region sometimes shifts to the lower relative pressure in case of microporous materials [23]. The micropore volume of the samples was evaluated by the Dubinin-Radushkevich (DR) equation [24] and the mesopore volume was determined by Dollimore-Heal (DH) method $[25,26]$ at the relative pressure of 0.95 .

Some samples were observed by a field emission scanning electron microscope (FE-SEM: JEOL, JSM-6330F, Japan) and a high-resolution transmission electron microscope (HR-TEM: JEOL, JEM2100, Japan).

\section{Results and discussion}

\subsection{Surface chemistry analysis of graphene oxide (GO) monolith, reduced graphene oxide (RGO) monolith and activated RGO (A-RGO) monolith}

Fig. 1(a-c) shows the $\mathrm{C}_{1 \mathrm{~s}}$ XPS spectra of as-prepared GO monolith, GO monoliths reduced at $573 \mathrm{~K}$ and $873 \mathrm{~K}$. The main peaks were deconvoluted using the Voigt function after the 
background subtraction with Shirley method [27]. The peak at $284.4 \mathrm{eV}$ is assigned to double bonding carbons for GO and RGOs, which is designated as " $\mathrm{C}=\mathrm{C}$ ". The peak at $285.5 \mathrm{eV}$ is assigned to a single bonding carbon, which is designated as " $\mathrm{C}-\mathrm{C}$ ". Some other peaks assigned to oxygen functional groups are observed at the higher binding energy region. They are $\mathrm{C}-\mathrm{O}$ at $286.1 \mathrm{eV}, \mathrm{C}=\mathrm{O}$ at $287.0 \mathrm{eV}$, and $\mathrm{COO}$ at $289.0 \mathrm{eV}[15,28,29]$. After the thermal reduction process, a distinct decrease of peaks at the high binding energy region is observed, indicating that oxygen functional groups are decomposed on the heating treatment.
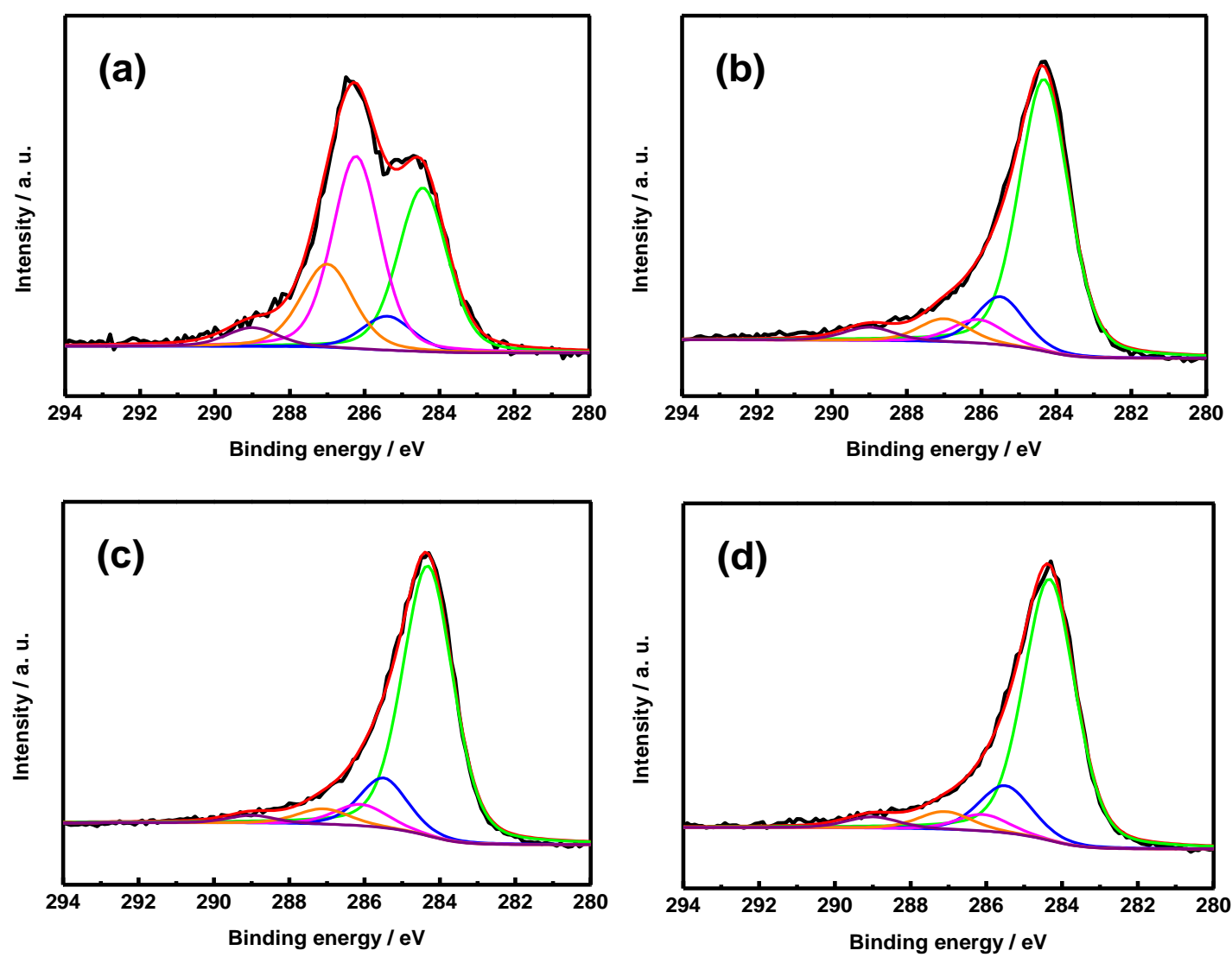

Fig. 1 - The $C_{1 \mathrm{~s}}$ XPS spectra and the deconvoluted spectra of (a) GO, (b) GO reduced at 573 $\mathrm{K}$, (c) GO reduced at $873 \mathrm{~K}$ and (d) RGO activated by $\mathrm{KOH}(\mathrm{KOH} / \mathrm{C}=5,1073 \mathrm{~K}, 1 \mathrm{~h})$. Carbon states: $\mathrm{C}=\mathrm{C}$ (green), $\mathrm{C}-\mathrm{C}$ (blue), $\mathrm{C}-\mathrm{O}$ (pink), $\mathrm{C}=\mathrm{O}$ (orange), $\mathrm{COO}$ (purple).

Table 1 lists the percents of each carbon state in GO and RGOs treated at different temperatures. The amount of the surface functional groups of RGO treated at $573 \mathrm{~K}$ is similar 
to that of the RGO treated at $873 \mathrm{~K}$. Even heating treatment at $573 \mathrm{~K}$ can reduce GO sufficiently and thereby heating at $573 \mathrm{~K}$ is used for reduction of all GO samples. Fig. 1(d) shows the XPS spectrum of high surface area A-RGO prepared from $\mathrm{KOH}$ activation $(\mathrm{KOH} / \mathrm{C}=5,1073 \mathrm{~K}, 1 \mathrm{~h})$, which will be discussed in Section 3.4.2.

Table 1. Percents of different carbon states in GO, RGO and A-RGO. Here RGO at $573 \mathrm{~K}$ and RGO at $873 \mathrm{~K}$ are RGO samples obtained by heating at $573 \mathrm{~K}$ and $873 \mathrm{~K}$, respectively.

\begin{tabular}{cccccc}
\hline Sample & $\mathrm{C}=\mathrm{C}(\%)$ & $\mathrm{C}-\mathrm{C}(\%)$ & $\mathrm{C}-\mathrm{O}(\%)$ & $\mathrm{C}=\mathrm{O}(\%)$ & $\mathrm{COO}(\%)$ \\
\hline GO & 35 & 6 & 37 & 17 & 5 \\
RGO at $573 \mathrm{~K}$ & 71 & 12 & 7 & 6 & 4 \\
RGO at $873 \mathrm{~K}$ & 75 & 13 & 6 & 4 & 2 \\
A-RGO & 74 & 13 & 5 & 5 & 3 \\
\hline
\end{tabular}

The electrical resistance of GO monoliths without reduction could not be measured due to the high resistance. While the electrical resistances of RGO monoliths treated at $573 \mathrm{~K}$ and $873 \mathrm{~K}$ were $(1.5 \pm 0.3) \mathrm{k} \Omega$ and $(1.4 \pm 0.3) \mathrm{k} \Omega$, respectively. The electrical resistance measurement supports that the heating treatment at $573 \mathrm{~K}$ can reduce GO sufficiently. Thus we can obtain low-density graphene monolith samples; the apparent densities of RGO monoliths treated at $573 \mathrm{~K}$ and $873 \mathrm{~K}$ were $(1.1 \pm 0.1) \times 10^{-2} \mathrm{~g} \mathrm{~cm}^{-3}$ and $(1.0 \pm 0.1) \times 10^{-2} \mathrm{~g}$ $\mathrm{cm}^{-3}$, respectively.

\section{2. $\mathrm{CO}_{2}$ activation method}

Fig. 2(a) and (b) show $\mathrm{N}_{2}$ adsorption isotherms at $77 \mathrm{~K}$ on non-activated RGO-I and those activated by $\mathrm{CO}_{2}$ at different conditions. The shapes of these isotherms are combination of type I and type II according to the IUPAC classification [30, 31]. The porosity parameters and burn off degree of RGO-I and RGO-I activated by $\mathrm{CO}_{2}$ at different conditions are shown in Table 2. Here $S_{\alpha \mathrm{s}}$ and $S_{\mathrm{BET}}$ are the SPE and BET surface areas, respectively; $V_{\mathrm{DR}}$ and $\mathrm{V}_{\mathrm{DH}}$ are 
the micropore volume from DR plot and the mesopore volume from DH method, respectively. The $S_{\alpha s}$ and $V_{D R}$ increase with the elevation of the activation temperature, and RGO-I obtained from $\mathrm{CO}_{2}$ activation at $1123 \mathrm{~K}$ for varying times also show higher $\mathrm{S}_{\alpha \mathrm{s}}$ and $\mathrm{V}_{\mathrm{DR}}$ with increasing activation time. However, the activation effect is not so obvious comparing with activation of ligneous precursors [32-34]. Thus the $\mathrm{CO}_{2}$ activation is not efficient for the production of micropores in RGO-I.
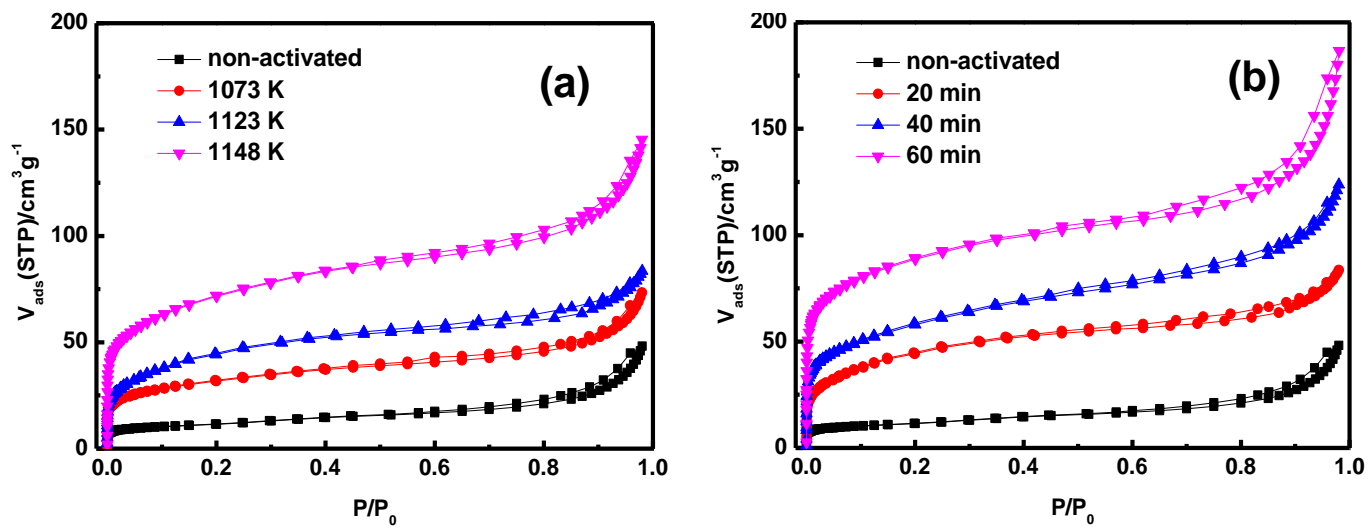

Fig. 2 - $\mathrm{N}_{2}$ adsorption isotherms of (a) RGO-I activated by $\mathrm{CO}_{2}$ at different temperatures for 20 min, (b) RGO-I activated by $\mathrm{CO}_{2}$ at $1123 \mathrm{~K}$ for different times.

Table 2 - Porosity parameters of RGO-I and RGO-I activated by $\mathrm{CO}_{2}$ at various conditions.

\begin{tabular}{ccccccc}
\hline Sample & $\begin{array}{c}\mathrm{S}_{\alpha \mathrm{s}} \\
\left(\mathrm{m}^{2} \mathrm{~g}^{-1}\right)\end{array}$ & $\begin{array}{c}\mathrm{S}_{\mathrm{BET}} \\
\left(\mathrm{m}^{2} \mathrm{~g}^{-1}\right)\end{array}$ & $\begin{array}{c}\mathrm{S}_{\mathrm{\alpha s}-\text { external }} \\
\left(\mathrm{m}^{2} \mathrm{~g}^{-1}\right)\end{array}$ & $\begin{array}{c}\mathrm{V}_{\mathrm{DR}} \\
\left(\mathrm{cm}^{3} \mathrm{~g}^{-1}\right)\end{array}$ & $\begin{array}{c}\mathrm{V}_{\mathrm{DH}} \\
\left(\mathrm{cm}^{3} \mathrm{~g}^{-1}, \pm 5 \%\right)\end{array}$ & $\begin{array}{c}\text { Burn off } \\
(\mathrm{wt} \%, \pm 5 \%)\end{array}$ \\
\hline RGO-I & 26 & 28 & -- & -- & -- & -- \\
$1073 \mathrm{~K}, 20 \mathrm{~min}$ & 110 & 113 & 32 & 0.04 & 0.07 & 22 \\
$1123 \mathrm{~K}, 20 \mathrm{~min}$ & 133 & 153 & 35 & 0.05 & 0.07 & 31 \\
$1148 \mathrm{~K}, 20 \mathrm{~min}$ & 240 & 257 & 63 & 0.09 & 0.11 & 53 \\
$1123 \mathrm{~K}, 40 \mathrm{~min}$ & 195 & 210 & 78 & 0.07 & 0.10 & 49 \\
$1123 \mathrm{~K}, 60 \mathrm{~min}$ & 320 & 320 & 79 & 0.12 & 0.15 & 72 \\
\hline
\end{tabular}

The SEM images of the product activated by $\mathrm{CO}_{2}$ with the highest surface area are shown in Fig. 3. The RGO-I monolith has a local unidirectional structure and the colonies of locally aligned region are observed, which is in the parallel directions of the ice front. This structure is similar to the previously reported materials which prepared by ice freezing method [16-18]. 
However, no ordered structure can be observed in the region within the colonies. Large numbers of nano-particles are observed in the magnified image of Fig. 3(b), which are derived from the metal residual in the GO preparation process. We activated RGO of high purity (RGO-P) by $\mathrm{CO}_{2}$ to obtain the products with less impurity, as mentioned in Section 2.1 .
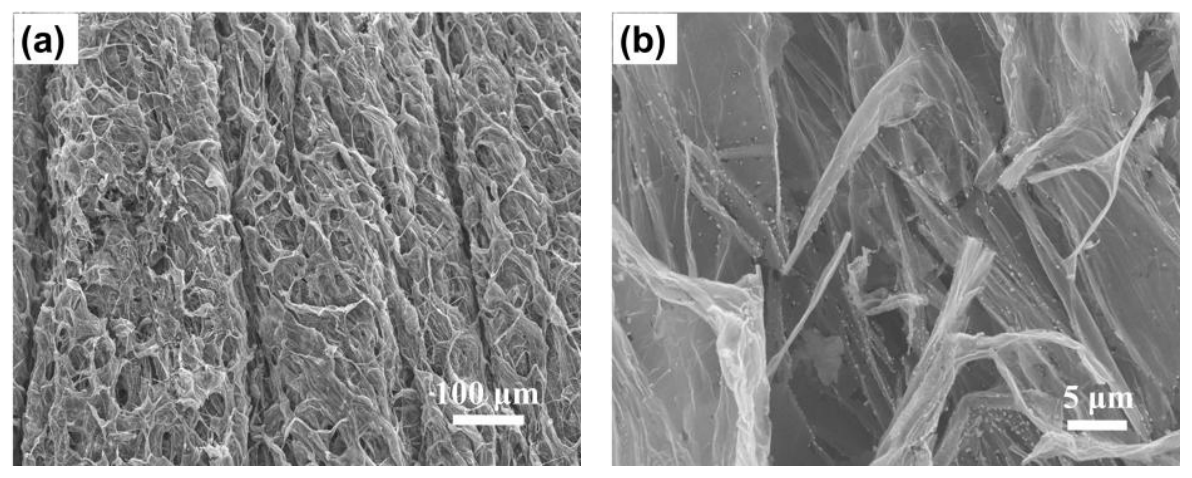

Fig. 3 - SEM images of RGO-I activated by $\mathrm{CO}_{2}$ at $1123 \mathrm{~K}$ for $60 \mathrm{~min}$.

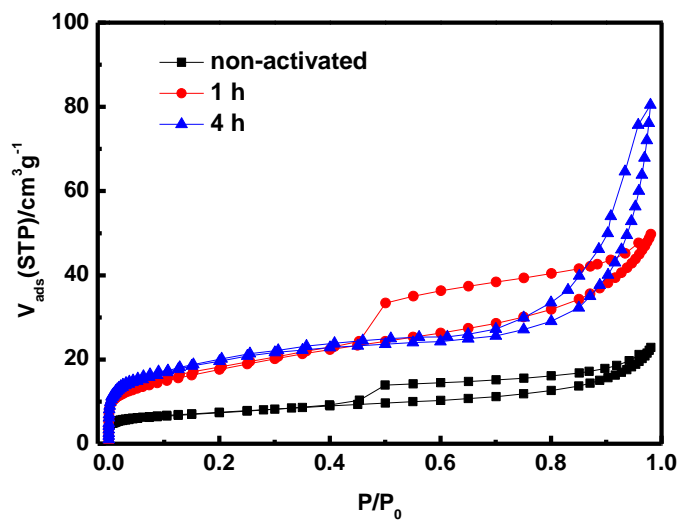

Fig. 4 - $\mathrm{N}_{2}$ adsorption isotherms of non-activated RGO-P and RGO-P activated by $\mathrm{CO}_{2}$ at $1223 \mathrm{~K}$ for $1 \mathrm{~h}$ and $4 \mathrm{~h}$.

Fig. 4 shows the adsorption isotherms of non-activated RGO-P and RGO-P monoliths activated by $\mathrm{CO}_{2}$ at $1223 \mathrm{~K}$ for $1 \mathrm{~h}$ and $4 \mathrm{~h}$. The adsorption isotherm of RGO-P activated for 1h has a hysteresis of type H4, being similar to that of RGO-P [30]. However the adsorption hysteresis of RGO-P activated for $4 \mathrm{~h}$ has a type H3, suggesting the broadening of slit-shaped mesopores after the longer activation. The maximum surface area $\left(S_{\alpha s}\right)$ of RGO-P activated 
for $4 \mathrm{~h}$ was $64 \mathrm{~m}^{2} \mathrm{~g}^{-1}$, being smaller than those obtained from RGO-I.

A small amount of metal in carbon can play a significant role in its gasification reaction according to Marsh et al [35]. The catalytic effects depend on the metal used, the metal particle size, the dispersion state in the carbon, the amount of metal present and the reaction temperature, etc. Accordingly, RGO-P of less impurities is not efficiently activated compared with RGO-I of more impurities; the surface area of activated RGO-I is smaller than that of activated RGO-I. Nevertheless, even the activation of RGO-I gives the surface area of $320 \mathrm{~m}^{2}$ $\mathrm{g}^{-1}$ at best, as shown in Table 2. Then the $\mathrm{CO}_{2}$ activation is not effective for RGO samples. This is because the $\mathrm{CO}_{2}$ molecules undergo reaction at the edges of the graphene planes (prismatic edges) rather than the basal planes [36]; the oxidation reaction at the prismatic edges are $10^{2}$ to $10^{3}$ times faster than that on the basal planes [37]. RGO has relatively large amount of basal planes than its prismatic edges comparing with other carbon materials, so that $\mathrm{CO}_{2}$ activation is not an effective method for RGO. Consequently, the RGO activation by $\mathrm{CO}_{2}$ with metal catalysts must be no appropriate route for development of the porosity.

\section{3. $\mathrm{ZnCl}_{2}$ and $\mathrm{H}_{3} \mathrm{PO}_{4}$ activation}
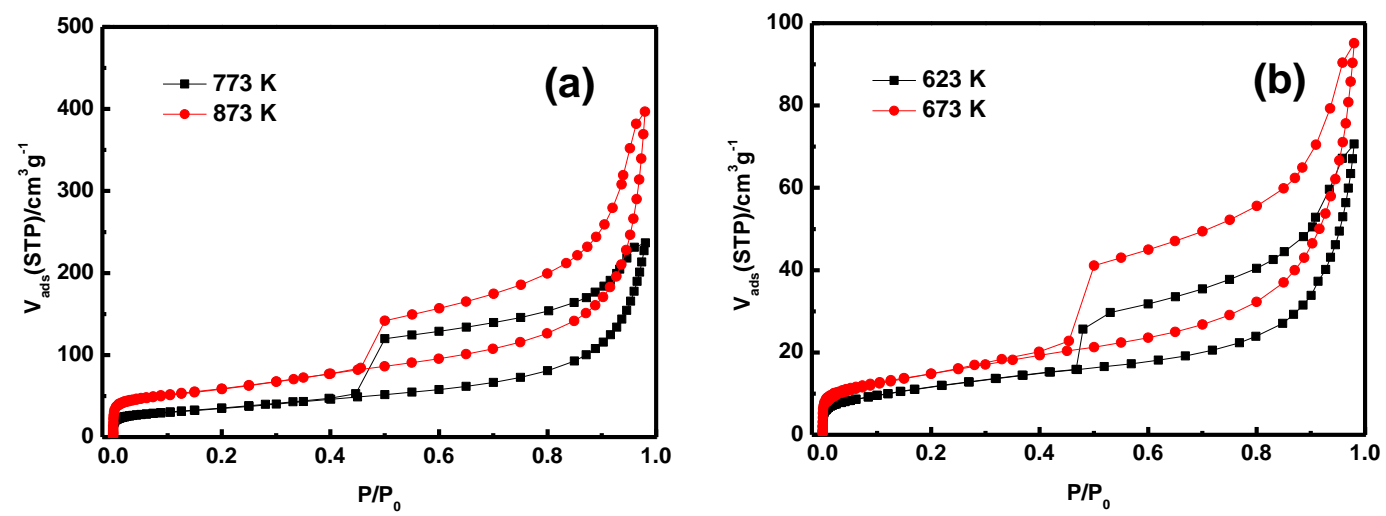

Fig.5 - $\mathrm{N}_{2}$ adsorption isotherms of $\mathrm{RGO}$ activated by (a) $\mathrm{ZnCl}_{2}$ and (b) $\mathrm{H}_{3} \mathrm{PO}_{4}$ at different temperatures for $1 \mathrm{~h}$.

The optimized activation conditions for RGO samples with $\mathrm{ZnCl}_{2}$ and $\mathrm{H}_{3} \mathrm{PO}_{4}$ are adopted 
from literature [38-40] and [41-43], respectively. The GO monoliths having $\mathrm{ZnCl}_{2}$ and $\mathrm{H}_{3} \mathrm{PO}_{4}$ were prepared from the mixture of $\mathrm{GO}$ suspension and $\mathrm{ZnCl}_{2}$ and $\mathrm{H}_{3} \mathrm{PO}_{4}$ at the weight ratio of carbon to chemical reagents of 1 to 1 , and then those were reduced as described in Section 2.2. The RGO monoliths containing $\mathrm{ZnCl}_{2}$ were activated at $773 \mathrm{~K}$ and $873 \mathrm{~K}$ for $1 \mathrm{~h}$, whereas the RGO monoliths containing $\mathrm{H}_{3} \mathrm{PO}_{4}$ were activated at $623 \mathrm{~K}$ and $673 \mathrm{~K}$ for $1 \mathrm{~h}$.

Table 3 - Porosity parameters of $\mathrm{RGO}$ activated by $\mathrm{ZnCl}_{2}$ and $\mathrm{H}_{3} \mathrm{PO}_{4}$ at various conditions.

\begin{tabular}{cccccc}
\hline $\begin{array}{c}\text { Activation } \\
\text { conditions }\end{array}$ & $\begin{array}{c}\mathrm{S}_{\alpha \mathrm{\alpha s}} \\
\left(\mathrm{m}^{2} \mathrm{~g}^{-1}\right)\end{array}$ & $\begin{array}{c}\mathrm{S}_{\mathrm{BET}} \\
\left(\mathrm{m}^{2} \mathrm{~g}^{-1}\right)\end{array}$ & $\begin{array}{c}\mathrm{S}_{\text {as-external }} \\
\left(\mathrm{m}^{2} \mathrm{~g}^{-1}\right)\end{array}$ & $\begin{array}{c}\mathrm{V}_{\mathrm{DR}} \\
\left(\mathrm{cm}^{3} \mathrm{~g}^{-1}\right)\end{array}$ & $\begin{array}{c}\mathrm{V}_{\mathrm{DH}} \\
\left(\mathrm{cm}^{3} \mathrm{~g}^{-1}, \pm 5 \%\right)\end{array}$ \\
\hline None & 24 & 26 & -- & -- & -- \\
$\mathrm{ZnCl}_{2}, 773 \mathrm{~K}, 1 \mathrm{~h}$ & 120 & 125 & 105 & 0.04 & 0.41 \\
$\mathrm{ZnCl}_{2}, 873 \mathrm{~K}, 1 \mathrm{~h}$ & 210 & 210 & 170 & 0.08 & 0.63 \\
$\mathrm{H}_{3} \mathrm{PO}_{4}, 623 \mathrm{~K}, 1 \mathrm{~h}$ & 36 & 40 & 33 & 0.01 & 0.09 \\
$\mathrm{H}_{3} \mathrm{PO}_{4}, 673 \mathrm{~K}, 1 \mathrm{~h}$ & 49 & 53 & 43 & 0.02 & 0.12 \\
\hline
\end{tabular}

Fig. 5(a) shows the $\mathrm{N}_{2}$ adsorption isotherms of $\mathrm{RGO}$ monoliths activated by $\mathrm{ZnCl}_{2}$ at 773

$\mathrm{K}$ and $873 \mathrm{~K}$. The isotherms are of typical type IV of the IUPAC classification. A distinct hysteresis with a steep uptake at high relative pressure is observed, indicating the presence of wide mesopores. The surface area evaluated by SPE method are 210 and $120 \mathrm{~m}^{2} \mathrm{~g}^{-1}$, and the corresponding external surface area are 105 and $170 \mathrm{~m}^{2} \mathrm{~g}^{-1}$, respectively, as shown in Table 3 . The similarity between SPE surface area and external surface area indicates that the $\mathrm{ZnCl}_{2}$-activation is not efficient for selective production of micropores. The mesopore volumes determined by DH method are rather large, being 0.41 and $0.63 \mathrm{~cm}^{3} \mathrm{~g}^{-1}$, respectively.

Fig. 5(b) shows the $\mathrm{N}_{2}$ adsorption isotherms of $\mathrm{RGO}$ monoliths activated by $\mathrm{H}_{3} \mathrm{PO}_{4}$ at 623 $\mathrm{K}$ and $673 \mathrm{~K}$. The shape of adsorption isotherms of the $\mathrm{H}_{3} \mathrm{PO}_{4}$-activation sample is similar to that of the $\mathrm{ZnCl}_{2}$-activation sample, but the adsorption amount is much less. Hence the 
activation with $\mathrm{H}_{3} \mathrm{PO}_{4}$ increases large mesoporosity and external surfaces, although it is less efficient than the activation with $\mathrm{ZnCl}_{2}$. The porosity parameters are shown in Table 3 . The surface area and micropore volume of these activated RGOs are too small compared with those of activated carbon produced by $\mathrm{ZnCl}_{2}$ or $\mathrm{H}_{3} \mathrm{PO}_{4}$ activation [38-43]. The $\mathrm{ZnCl}_{2}$ or $\mathrm{H}_{3} \mathrm{PO}_{4}$ activation induces marked dehydration effect on the cellulose, hemicellulose and lignin compounds in the carbon precursor during heat treatment [37]. However, the graphene based materials like RGO has less aquo-complexes and thereby the activation with $\mathrm{ZnCl}_{2}$ or $\mathrm{H}_{3} \mathrm{PO}_{4}$ does not develop the porosity, as mentioned above.

\subsection{KOH activation}

The mechanism of the chemical activation of carbons by $\mathrm{KOH}$ is very different from that by $\mathrm{ZnCl}_{2}$ or $\mathrm{H}_{3} \mathrm{PO}_{4}$. Instead of developing the porosity by the dehydrating effect, $\mathrm{KOH}$ activation consists of a series of redox reactions where carbon is oxidized to $\mathrm{CO}, \mathrm{CO}_{2}$ and carbonate, while $\mathrm{KOH}$ is reduced into $\mathrm{K}_{2} \mathrm{CO}_{3}$ or metallic potassium [44-46]. The porosity can be developed from the gasification and separation of graphene layers in the graphitic structure. Therefore, the $\mathrm{KOH}$ activation appears to be a more promising route for activation of RGO. In this work, we examined the effect of the activation temperature and the $\mathrm{KOH}$ to carbon weight ratio, as the amount of $\mathrm{KOH}$ and the reaction temperature have a strong effect on the porosity development $[35,47,48]$.

\subsubsection{Structure evolution during activation of RGO monolith}

Fig. 6 shows the SEM images of the RGO samples before activation and RGO activated at $1073 \mathrm{~K}$ with different $\mathrm{KOH}$ to carbon ratio $(\mathrm{KOH} / \mathrm{C})$. The RGO consists of many crumpled sheets, which are detached from each other and construct a lot of macroporous space. The 
sheets start to aggregate into agglomerates and the surface of these sheet become more crumpled by the $\mathrm{KOH}$ activation at $\mathrm{KOH} / \mathrm{C}=1$. A thick wall structure can be observed at $\mathrm{KOH} / \mathrm{C}=3$, indicating the formation of highly aggregated structure. The thickness of the wall structure further increases in the case of $\mathrm{KOH} / \mathrm{C}=5$. The morphology change from the detached graphene sheets to the thick lamellar structure should come from the aggregation of GO suspensions caused by the neutralization of its surface charge with $\mathrm{KOH}$. On the other hand, the effect of $\mathrm{KOH}$ activation at high temperature can also modify the surface nano-structure, which can be analyzed by the $\mathrm{N}_{2}$ adsorption experiment.
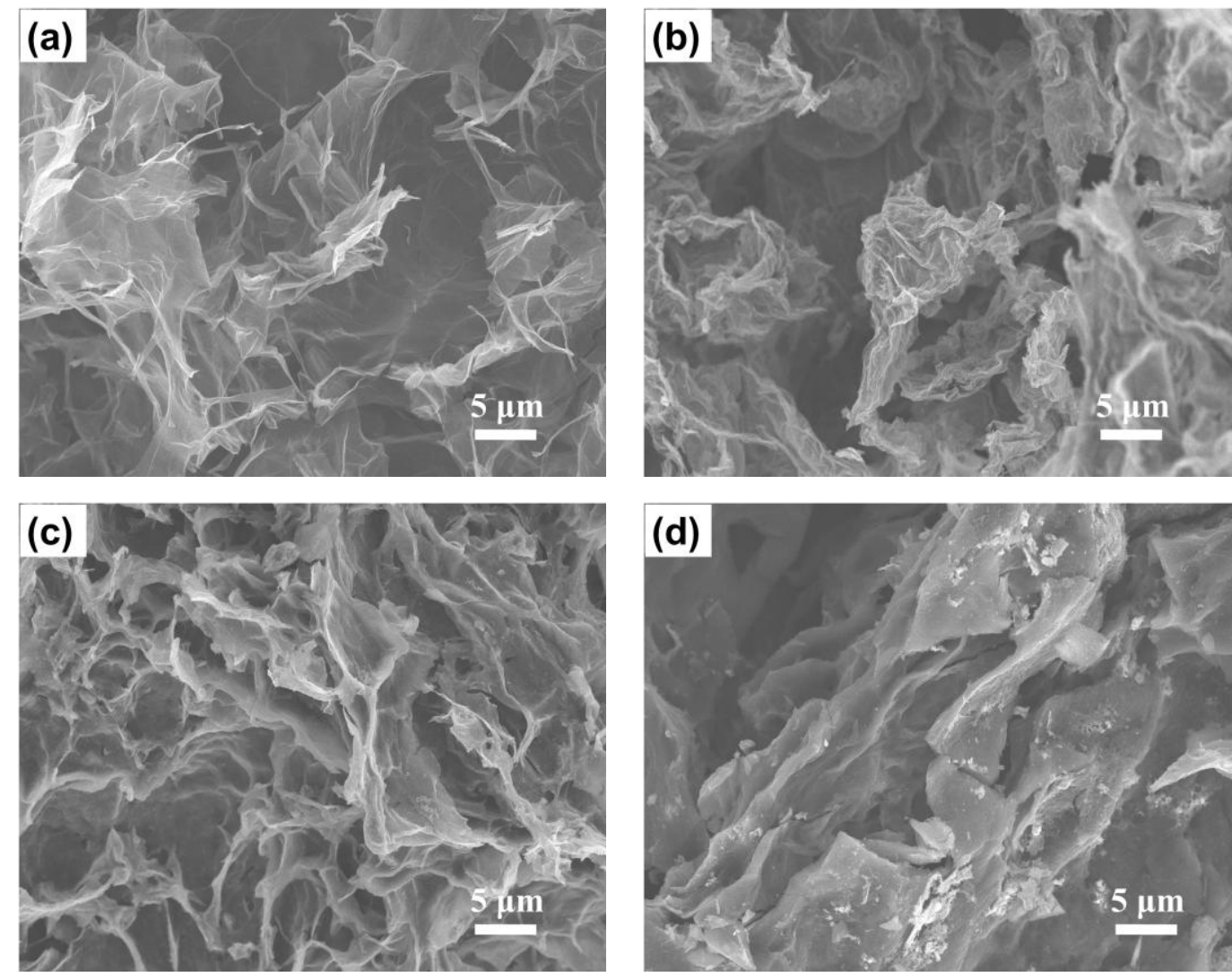

Fig. 6 - SEM images of (a) RGO before activation and RGO activated at $1073 \mathrm{~K}$ for $1 \mathrm{~h}$ with $\mathrm{KOH} / \mathrm{C}$ of (b) 1 ; (c) 3 ; (d) 5 .

\subsubsection{Porosity evolution on activation of $R G O$ monoliths}

Fig. 7(a) shows the $\mathrm{N}_{2}$ adsorption isotherms of RGO prepared by $\mathrm{KOH}$ activation with 
$\mathrm{KOH} / \mathrm{C}=1$ at different temperatures for $1 \mathrm{~h}$. The adsorption isotherms are of type IV with a slight combination of type I, indicating the presence of predominant mesopores with a little contribution of microporosity for the $\mathrm{KOH}$-activated samples, although the RGO contains a small amount of mesoporosity and almost no microporosity. The KOH-activation shows an evident enhancement of $\mathrm{N}_{2}$ uptake at whole relative pressure range. Also, the RGO prepared at $1073 \mathrm{~K}$ shows slightly higher $\mathrm{N}_{2}$ uptake than those prepared at 973 and $1023 \mathrm{~K}$, which are very close to each other. In case of $\mathrm{KOH} / \mathrm{C}=1$, the frameworks of macropores should be broken into smaller and randomly arranged pieces, leading to the increase of mesoporosity. Also, the metallic potassium produced from the redox reaction between $\mathrm{KOH}$ and carbon species can be intercalated between the graphene walls, being responsible for the development of microporosity by the separation, gasification, and degradation of the graphene layers $[49,50]$, even if microporosity development is still not so remarkable. Fig. 7(b) shows the type I $\mathrm{N}_{2}$ adsorption isotherms of the RGOs activated at $\mathrm{KOH} / \mathrm{C}=2$, being different from those at $\mathrm{KOH} / \mathrm{C}=1$. This indicates that the mesopores are deteriorated while micropores are further developed. A slight adsorption increase is observed near $\mathrm{P} / \mathrm{P}_{0}=1$ for all adsorption isotherms and thereby some wide mesopores and/or macropores still remain after this activation. The adsorption isotherms of the $\mathrm{RGO}$ activated at $\mathrm{KOH} / \mathrm{C}=3$ have a significant enhancement of $\mathrm{N}_{2}$ uptake in the low relative pressure range, as shown in Fig. 7(c), indicating the striking development of the micropores. A gradual adsorption increase is observed in the $\mathrm{P} / \mathrm{P}_{0}$ range up to 0.4 , which stems from the presence of larger micropores [21]. The adsorption is almost saturated above $\mathrm{P} / \mathrm{P}_{0}=0.5$, being indicative of disappearance of wide mesopores and macropores. On the other hand, a hysteresis loop can be observed 
between 0.4 and 0.6 of $\mathrm{P} / \mathrm{P}_{0}$ for $\mathrm{RGO}$ activated at $1023 \mathrm{~K}$ and $1073 \mathrm{~K}$, which stems from the presence of small mesopores. The newly developed small mesoporosity is attributed to the continuous enlargement of micropores by degradation and gasification of graphene units. Furthermore, when $\mathrm{KOH} / \mathrm{C}=5$, the initial $\mathrm{N}_{2}$ uptake in the low relative pressure range is larger than those at $\mathrm{KOH} / \mathrm{C}=3$, being indicative of the further development of microporosity. No distinct uptake is observed above $\mathrm{P} / \mathrm{P}_{0}=0.4$ for $\mathrm{RGO}$ activated at $973 \mathrm{~K}$, and then the structure mainly consists of microporosity. On the contrary the activation at $1023 \mathrm{~K}$ and 1073 $\mathrm{K}$ induces the continuous increase of $\mathrm{N}_{2}$ adsorption even above $\mathrm{P} / \mathrm{P}_{0}=0.4$ with a distinct hysteresis loop, indicating the notable development of mesoporosity from the continuous enlargement of micropores. The adsorption hysteresis loops belong to Type $\mathrm{H} 2$ according to IUPAC classification [30]. The H2 loop was attributed to different mechanism in the condensation and evaporation processes occurring in pores having narrow necks and wide bodies ('ink bottle' pores) in the past. However, this model neglects network effects of mesopores [30] and then we cannot clearly conclude that these RGO samples have "ink bottle" type mesopores.

The porosity parameters of RGOs activated at different conditions with $\mathrm{KOH}$ are shown in Table 4. Fig. 8 illustrates the porosity parameters as a function of the activation temperature and $\mathrm{KOH} / \mathrm{C}$. 

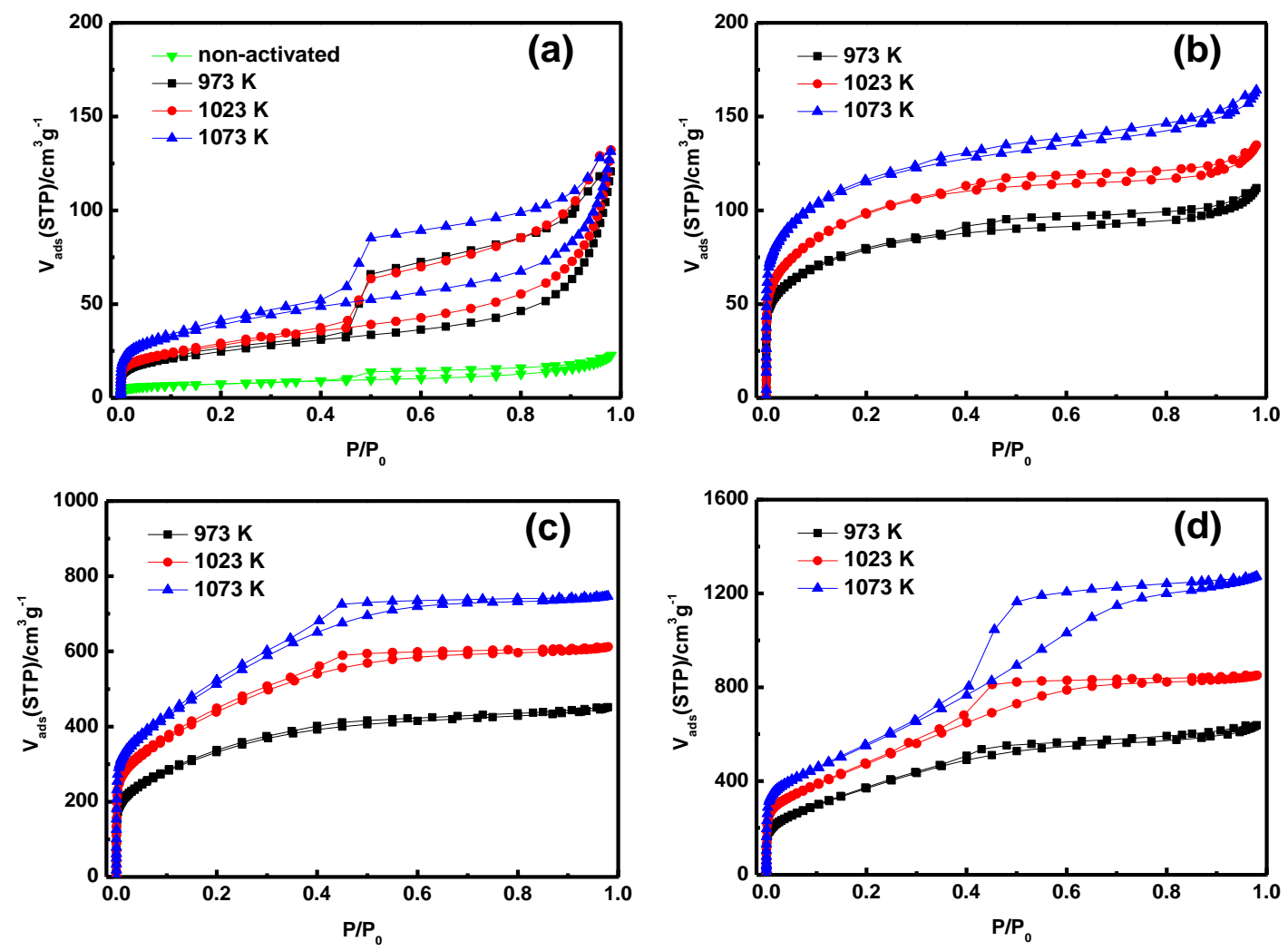

Fig. $7-\mathrm{N}_{2}$ adsorption isotherms of RGO activated at different temperatures with $\mathrm{KOH} / \mathrm{C}=1$ (a), 2 (b), 3 (c) and 5(d) for $1 \mathrm{~h}$.

Table 4 - Porosity parameters for RGO activated by $\mathrm{KOH}$ at various conditions.

\begin{tabular}{rccccc}
\hline Activation conditions & $\begin{array}{c}\mathrm{S}_{\alpha \mathrm{s}} \\
\left(\mathrm{m}^{2} \mathrm{~g}^{-1}\right)\end{array}$ & $\begin{array}{c}\mathrm{S}_{\mathrm{BET}} \\
\left(\mathrm{m}^{2} \mathrm{~g}^{-1}\right)\end{array}$ & $\begin{array}{c}\mathrm{S}_{\alpha \text { s-external }} \\
\left(\mathrm{m}^{2} \mathrm{~g}^{-1}\right)\end{array}$ & $\begin{array}{c}\mathrm{V}_{\mathrm{DR}} \\
\left(\mathrm{cm}^{3} \mathrm{~g}^{-1}\right)\end{array}$ & $\begin{array}{c}\mathrm{V}_{\mathrm{DH}} \\
\left(\mathrm{cm}^{3} \mathrm{~g}^{-1}, \pm 5 \%\right)\end{array}$ \\
\hline None & 24 & 26 & -- & -- & -- \\
$\mathrm{KOH} / \mathrm{C}=1,973 \mathrm{~K}$ & 78 & 87 & 54 & 0.02 & 0.19 \\
$1023 \mathrm{~K}$ & 90 & 100 & 68 & 0.03 & 0.2 \\
$1073 \mathrm{~K}$ & 123 & 123 & 86 & 0.05 & 0.19 \\
$\mathrm{KOH} / \mathrm{C}=2,973 \mathrm{~K}$ & 270 & 270 & 28 & 0.10 & 0.04 \\
$1023 \mathrm{~K}$ & 320 & 335 & 20 & 0.11 & 0.04 \\
$1073 \mathrm{~K}$ & 405 & 415 & 65 & 0.14 & 0.07 \\
$\mathrm{KOH} / \mathrm{C}=3,973 \mathrm{~K}$ & 1060 & 1100 & 80 & 0.39 & 0.12 \\
$1023 \mathrm{~K}$ & 1400 & 1450 & 58 & 0.53 & 0.14 \\
$1073 \mathrm{~K}$ & 1645 & 1765 & 50 & 0.61 & 0.24 \\
$\mathrm{KOH} / \mathrm{C}=5,973 \mathrm{~K}$ & 1080 & 1160 & 185 & 0.42 & 0.31 \\
$1023 \mathrm{~K}$ & 1450 & 1510 & 100 & 0.59 & 0.52 \\
$1073 \mathrm{~K}$ & 1760 & 1840 & 325 & 0.67 & 1.33 \\
$\mathrm{KOH} / \mathrm{C}=10,1073 \mathrm{~K}$ & 2150 & 2200 & 360 & 0.81 & 1.36 \\
\hline
\end{tabular}



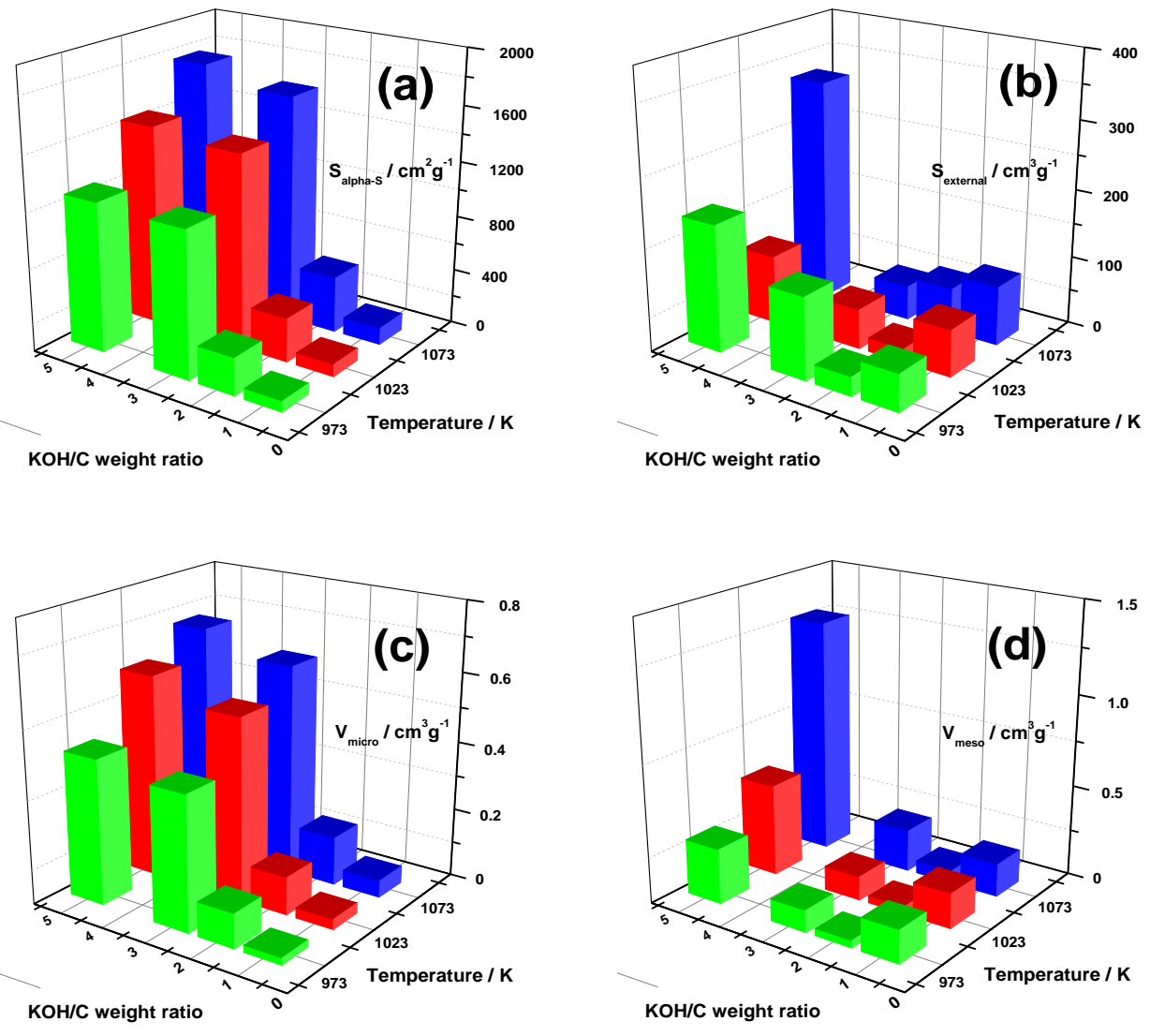

Fig. 8 - Three dimensional histograms of surface area by $\alpha_{\mathrm{s}}$-plot and pore volume of RGOs activated at different temperature and $\mathrm{KOH} / \mathrm{C}$ ratio.

The surface area from the $\alpha_{\mathrm{s}}$-plot increases with the $\mathrm{KOH} / \mathrm{C}$ ratio at the same activation temperature, while surface area increases with the activation temperature at the same $\mathrm{KOH} / \mathrm{C}$ ratio. The steep jump between the samples prepared with $\mathrm{KOH} / \mathrm{C}$ ratio of 2 and 3 indicates the remarkable development of microporosity within this $\mathrm{KOH} / \mathrm{C}$ ratio range. The external surface areas from $\alpha_{\mathrm{s}}$-plot method are shown in Fig. 8(b). The external surface area drops and then increases with the increase of $\mathrm{KOH} / \mathrm{C}$ ratio at the same activation temperature. As we prefer graphene having higher surface area and less external surface for future application, we can choose the promising activation conditions from Fig. 8(a) and (b); activation at $1073 \mathrm{~K}$ and $\mathrm{KOH} / \mathrm{C}=3$ should be appropriate for production of the high performance adsorbent, for 
example. Fig. 8(c) shows the changes of the micropore volume. The micropore volume increases with the activation temperature and $\mathrm{KOH} / \mathrm{C}$ ratio; there is a steep jump between the $\mathrm{KOH} / \mathrm{C}$ ratio of 2 and 3. Fig. 8(d) shows the variations of the mesopore volume. Generally speaking, the mesoporosity is not predominant compared with the microporosity except for $\mathrm{RGO}$ activated at $\mathrm{KOH} / \mathrm{C}=5$. The mesopore volume increases markedly with the activation temperature at $\mathrm{KOH} / \mathrm{C}=5$. The $\mathrm{RGO}$ activated at $1073 \mathrm{~K}$ and $\mathrm{KOH} / \mathrm{C}=5$ has the largest mesoporosity and microporosity, having a great application potential.
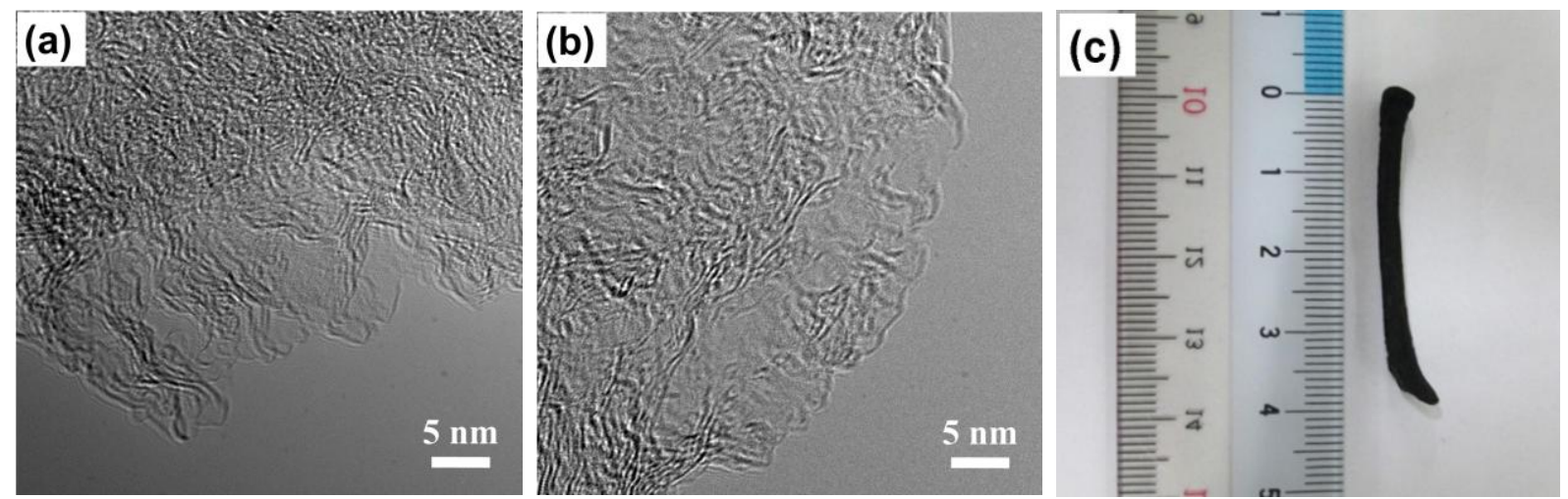

Fig. 9 - High-resolution TEM images and a photo of RGO activated by $\mathrm{KOH}$ at $1073 \mathrm{~K}$ with $\mathrm{KOH} / \mathrm{C}=5$.

Fig. 9 shows high resolution TEM images and a photo of the graphene monoliths from RGO activated at $1073 \mathrm{~K}$ with $\mathrm{KOH} / \mathrm{C}=5$, having the largest surface area in Fig. 8. Three dimensional networks of carbon sheets with entangled and crumpled structures are observed, being responsible for the presence of the meso- and microporosity. The carbon sheets mainly consist of monolayer or few-layer graphene sheets of considerably large size, which is very different from conventional activated carbons (or activated carbon fibers) of high surface area which mainly consist of tiny carbon units of several nanometers at a maximum in the scale [51-53]. The graphene-based frameworks developed in this work are expected to be more 
mechanically and chemically stable. The graphene monoliths activated at $1073 \mathrm{~K}$ with $\mathrm{KOH} / \mathrm{C}=5$, having a surface area of $1760 \mathrm{~m}^{2} \mathrm{~g}^{-1}$, still maintain their free standing nature, as shown in Fig. 9(c). The free standing monolith is really promising in the application fields such as catalysis [54, 55], electrochemistry [56, 57], sensors [58], energy storage [59] and environment technologies [60]. In this aspect, we need to design the robust graphene monolith of high surface area in future. The ash content of this sample is only $1.4 \mathrm{wt} \%$, which is very close to that of RGO-P, being $1.3 \mathrm{wt} \%$, indicating that $\mathrm{KOH}$ intercalated in graphene layers during activation process can be mostly removed by the simple water washing. The surface chemistry analysis of the high surface area A-RGO is shown in Fig. 1(d) and Table 1. The A-RGO has a small amount of oxygen functional groups similar to those of GO reduced at $873 \mathrm{~K}$. The apparent density of high surface area A-RGO monoliths ranges from $30-65 \mathrm{mg}$ $\mathrm{cm}^{-3}$ depending on the preparation and activation conditions. These densities are higher than that of the non-activated RGO monoliths due to the compaction of the monoliths in the preparation stage, as describe in Section 2.2. It is noteworthy that A-RGO has a considerably high electrical conductivity. (electrical resistance: $(1.5 \pm 0.3) \mathrm{k} \Omega$, being close to that of non-activated RGO monolith, whereas the apparent density of this A-RGO monolith is about 3 times larger than that of non-activated one.)

\subsubsection{Activation model of reduced graphene oxide monoliths with $\mathrm{KOH}$}

The changes in microporosity and mesoporosity of the RGO samples with the $\mathrm{KOH}$ activation enable us to propose the activation model of the RGO. We assume the unit plate as monolayer graphene with thickness of $0.355 \mathrm{~nm}$. The non-activated RGO consists of randomly bridged carbon sheets with many stacked graphene layers, as shown in Fig. 10(a). 
The interspaces constructed by such randomly bridged carbon sheets are too large to be analyzed with $\mathrm{N}_{2}$ adsorption, giving a small surface area. Activation with $\mathrm{KOH} / \mathrm{C}=1$ separates the thick carbon sheets into thinner and finer graphene layers, as shown in Fig. 10(b), correspondingly the macroporous frameworks collapse into smaller interspaces, leading to the formation of mesoporosity. The carbon sheets start to separate to much smaller pieces with fewer graphene layers at $\mathrm{KOH} / \mathrm{C}=2$, as shown in Fig. $10(\mathrm{c})$, even if some mesoporous spaces still remain under this activation condition. The separated thin graphene layers can form a highly porous assembly due to their partial interstacking. As the predominant surface area should come from the basal plane of the graphene sheets, the average graphene layer number is estimated to be 6.5 at this stage from the surface area [61, 62]. The remained mesoporous space is filled with newly produced single and/or few layers of graphene, when $\mathrm{KOH} / \mathrm{C}=3$, as shown in Fig. 10(d). In this case, surface area gives 1.6 layer number of graphene, supporting this model structure. The $\mathrm{KOH}$ activation with the condition of $\mathrm{KOH} / \mathrm{C}=5$ exfoliates more the few graphene layers into the single layer. At the same time, gasification proceeds from the edges of the extremely thin graphene layers to form mesopores, as shown in Fig. 10(e). A more intensive activation using the $\mathrm{KOH} / \mathrm{C}=10$ condition increases both of meso- and microporosity, as shown in Table 4. Thus, this activation model can describe the whole experimental results on the porosity and TEM observation. Therefore, this model is helpful to design an optimum activation process for the target porosity, although we need to take into account the contribution of the edge carbons in future. The model cannot be applied to the conventional activated carbon which is not produced from the well-defined unit carbon structures. 

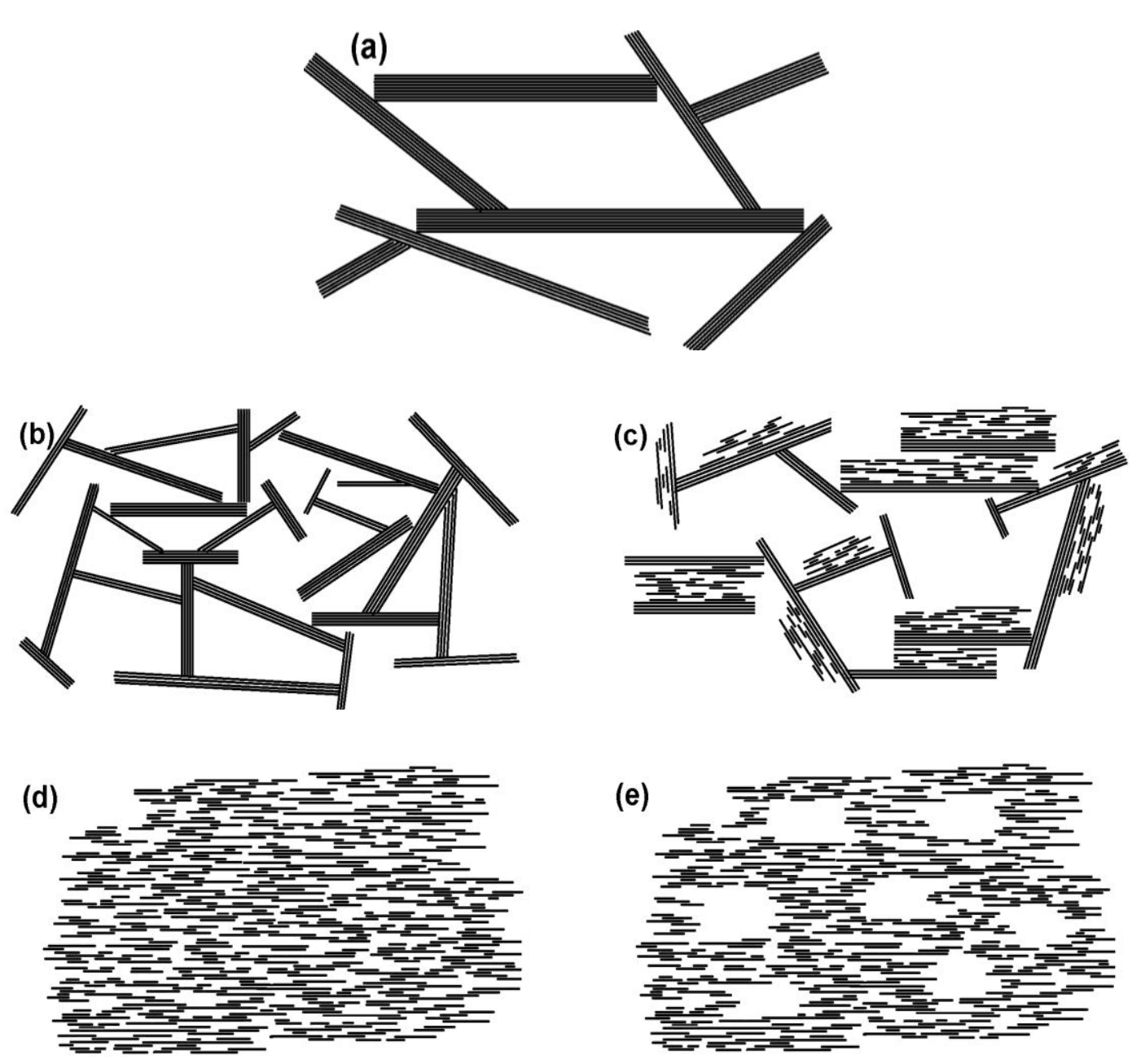

Fig. 10 - Model of the porosity development on (a) non-activated RGO and RGO activated at $1073 \mathrm{~K}$ with $\mathrm{KOH} / \mathrm{C}=1$ (b), 2 (c), 3 (d) and 5(e) for $1 \mathrm{~h}$.

\section{Conclusions}

This work shows that the $\mathrm{KOH}$ activation method is highly efficient for production of the high surface area graphene monolith. The porosity development of the reduced graphene oxide monoliths with the $\mathrm{KOH}$ activation can be interpreted by the following activation scheme:

1. Development of mesoporosity by partial exfoliation of thick graphene sheets accompanying with reconstruction of the thinner sheets. 
2. Marked microporosity development by full occupancy of the void spaces with monolayer and/or few layers graphene sheets.

3. Formation of bimodal pore structured graphene-based carbon with mesoporosity and microporosity due to the further exfoliation and partial gasification of the edges of the graphene sheets.

The above activation gives the porous graphene monolith with high surface area of 2150 $\mathrm{m}^{2} \mathrm{~g}^{-1}$ at most. The walls of the porous graphene monolith of the highest surface area should be close to single graphene layers taking account of the loss in the surface area due to the inter-insertion structure. The newly developed graphene monolith has a great application potential. Besides, this work provides a promising route for the bottom-up design of pore width-tunable nanoporous carbons.

Acknowledgement: K. K., F. T., T. F., R. C-S, M. T. and M. E. were supported by Exotic Nanocarbons, Japan Regional Innovation Strategy Program by the Excellence, JST. This work was supported by Grant-in-Aid for Scientific Research (A) (24241038) and Concert-Japan project: Efficient Energy Storage and Distribution, JST. D. M., and this study were partially supported by JST CREST “Creation of Innovative Functional Materials with Advanced Properties by Hyper-nano-space Design".

\section{Reference}

[1] Imai J, Souma M, Ozeki S, Suzuki T, Kaneko K. Reaction of dimerized $\mathrm{NO}_{\mathrm{x}}(\mathrm{x}=1$ or 2) with sulfur dioxide in a restricted slit-shaped micropore space. J Phys Chem 1991; 95 (24): 9955-9960.

[2] Miyamoto J, Hattori Y, Noguchi D, Tanaka H, Ohba T, Utsumi S, et al. Efficient $\mathrm{H}_{2}$ 
adsorption by nanopores of high-purity double-walled carbon nanotubes. J Am Chem Soc 2006; 128 (39): 12636-12637.

[3] Zhu Y, Murali S, Stoller MD, Ganesh KJ, Cai W, Ferreira PJ, et al. Carbon-based supercapacitors produced by activation of graphene. Science 2011; 332: 1537-1541.

[4] Bourrelly S, Llewellyn PL, Serre C, Millange F, Loiseau T, Férey G. Different adsorption behaviors of methane and carbon dioxide in the isotypic nanoporous metal terephthalates MIL-53 and MIL-47. J Am Chem Soc 2005; 127(39): 13519-13521.

[5] Wang S, Itoh T, Fujimori T, Castro MM, Silvestre-Albero A, Rodríguez-Reinoso F, et al. Formation of $\mathrm{CO}_{\mathrm{x}}$-free $\mathrm{H}_{2}$ and cup-stacked carbon nanotubes over nano-Ni dispersed single wall carbon nanohorns. Langmuir 2012; 28 (19): 7564-7571.

[6] Ouyang M, Huang JL, Lieber CM. Fundamental electronic properties and applications of single-walled carbon nanotubes. Acc. Chem. Res. 2002; 35 (12): 1018-1025.

[7] Hone J, Whitney M, Piskoti C, Zettl A. Thermal conductivity of single-walled carbon nanotubes. Phys Rev B 1999; 59(4): R2514-R2516.

[8] Hummer G, Rasaiah JC, Noworyta JP. Water conduction through the hydrophobic channel of a carbon nanotube. Nature 2001; 414(8): 188-190.

[9] Kaneko K, Itoh T, Fujimori T. Collective interactions of molecules with an interfacial solid. Chem Lett 2012; 41(5): 466-475.

[10] Thornton AW, Hilder T, Hill AJ, Hill JM. Predicting gas diffusion regime within pores of different size, shape and composition. J Membrane Sci 2009; 336(1-2): 101-108.

[11] Jagoda-Cwiklik B, Cwiklik L, Frankowicz M. Theoretical study of the influence of confinement and channel blocking on adsorption and diffusion of n-butane in silicalite- 1 . 
Appl Surf Sci 2005; 252(3): 699-706.

[12] Tatsuda N, Yano K. Pore size control of monodispersed starburst carbon spheres. Carbon $2013 ; 51: 27-35$.

[13] Tran C, Kalra V. Fabrication of porous carbon nanofibers with adjustable pore sizes as electrodes for supercapacitors. J Power Source 2013; 235: 289-296.

[14] Barrera D, Dávila M, Cornette V, Alexandre de Oliveira JC, López RH, Sapag K. Pore size distribution of ordered nanostructured carbon CMK-3 by means of experimental techniques and Monte Carlo simulations. Micropor Mesopor Mat 2013; 180: 71-78.

[15] Marcano DC, Kosynkin DV, Berlin JM, Sinitskii A, Sun Z, Slesarev A, et al. Improved synthesis of graphene oxide. ACS Nano 2010; 4 (8): 4806-4814.

[16] Mukai SR, Nishihara H, Tamon H. Formation of monolithic silica gel microhoneycombs (SMHs) using pseudosteady state growth of microstructural ice crystals. Chem Commun $2004 ; 874-875$.

[17] Zhang N, Qiu H, Si Y, Wang W, Gao J. Fabrication of highly porous biodegradable monoliths strengthened by graphene oxide and their adsorption of metal ions. Carbon 2011; 49 (3): 827-837.

[18] Wen P, Gao J, Zhang Y, Liu Y. Fabrication of chitosan scaffolds with tunable porous orientation structure for tissue engineering. J Biomater Sci, Polym Ed 2011; 22 (1-3): 19-40. [19] Fukasawa J, Tsujii K. Higher-order structure formation of ultrafine boehmite particles in sols, gels, and dried materials. J Colloid Interface Sci 1988; 125(1): 155-161.

[20] Fukasawa J, Tsutsumi H, Sato M, Kaneko K. Molecular resolution analysis of microporous oriented boehmite aggregates. Langmuir 1994; 10 (8): 2718-2721. 
[21] Setoyama N, Suzuki T, Kaneko K. Simulation study on the relationship between a high resolution $\alpha_{\mathrm{s}}$-plot and the pore size distribution for activated carbon. Carbon 1998; 36(10): $1459-1467$.

[22] Yang CM, Kaneko K, Yudasaka M, Iijima S. Effect of purification on pore structure of HiPco single-walled carbon nanotube aggregates. Nano Lett 2002; 2(4): 385-388.

[23] Kaneko K, Ishii C, Ruike M, kuwabara H. Origin of superhigh surface area and microcrystalline graphitic structures of activated carbons. Carbon 1992; 30(7): 1075-1088.

[24] Dubinin MM. Fundamentals of the theory of adsorption in micropores of carbon adsorbents: Characteristics of their adsorption properties and microporous structures. Carbon 1989; 27(3): 457-467.

[25] Dollimore D, Heal GR. An improved method for the calculation of pore size distribution from adsorption data. J Applied Chem 1964; 14(3): 109-114.

[26] Dollimore D, Heal GR. Pore-size distribution in typical adsorbent systems. J Colloid Interface Sci 1970; 33(4): 508-519.

[27] Shirley DA. High-Resolution X-Ray photoemission spectrum of the valence bands of gold. Phys Rev B 1972; 5(12): 4709-4714.

[28] Utsumi S, Honda H, Hattori Y, Kanoh H, Iijima S, Kaneko K. Direct evidence on C-C single bonding in single-wall carbon nanohorn aggregates. J Phys Chem C 2007; 111(15): $5572-5575$.

[29] Shen J, Li T, Long Y, Shi M, Li N, Ye M. One-step solid state preparation of reduced graphene oxide. Carbon 2012; 50(6): 2134-2140.

[30] Sing KSW, Everett DH, Haul RAW, Moscou L, Pierotti RA, Rouquerol J, 
Siemieniewska T. Reporting physisorption data for gas/solid systems with special reference to the determination of surface area and porosity. Pure \& Appl Chem 1985; 57(4): 603-619. [31] Rouquerol J, Avnir D, Fairbridge CW, Everett DH, Haynes JM, Pernicone N, et al. Recommendations for the characterization of porous solids. Pure \& Appl Chem 1994; 66(8): $1739-1758$.

[32] Turmuzi M, Daud WRW, Tasirin SM, Takriff MS, Iyuke SE. Production of activated carbon from candlenut shell by $\mathrm{CO}_{2}$ activation. Carbon 2004; 42 (2): 453-455.

[33] Molina-Sabio M, Gonzalez MT, Rodríguez-Reinoso F, Sepúlveda-Escribano A. Effect of steam and carbon dioxide activation in the micropore size distribution of activated carbon. Carbon 1996; 34(4): 505-509.

[34] Pastor-Villegas J, Durán-Valle CJ. Pore structure of activated carbons prepared by carbon dioxide and steam activation at different temperatures from extracted rockrose. Carbon 2002; 40(3): 397-402.

[35] Marsh H, Taylor DA, Lander JR. Kinetic study of gasification by oxygen and carbon dioxide of pure and doped graphitizable carbons of increasing heat treatment temperatures. Carbon 1981; 19(5): 375-381.

[36] Asai M, Ohba T, Iwanaga I, Kanoh H, Endo M, Campos-Delgado J, et al. Marked adsorption irreversibility of graphitic nanoribbons for $\mathrm{CO}_{2}$ and $\mathrm{H}_{2} \mathrm{O}$. J Am Chem Soc 2011; 133(38): 14880-14883.

[37] Marsh H, Rodríguez-Reinoso F. Activated carbon. London: Elsevier. 2006: 268, $330-331$.

[38] Caturla F, Molina-Sabio M, Rodríguez-Reinoso F. Preparation of activated carbon by 
chemical activation with $\mathrm{ZnCl}_{2}$. Carbon 1991; 29(7): 999-1007.

[39] Yorgun S, Vural N, Demiral H. Preparation of high-surface area activated carbons from Paulownia wood by $\mathrm{ZnCl}_{2}$ activation. Micropor Mesopor Mat 2009; 122(1-3): 189-194.

[40] Olivares-Marín M, Fernández-González C, Macías-García A, Gómez-Serrano V. Preparation of activated carbon from cherry stones by chemical activation with $\mathrm{ZnCl}_{2}$. Appl Surf Sci 2006; 252(17): 5967-5971.

[41] Molina-Sabio M, Rodríguez-Reinoso F, Caturla F, Sellés MJ. Porosity in granular carbons activated with phosphoric acid. Carbon 1995; 33(8): 1105-1113.

[42] Teng H, Yeh TS, Hsu LY. Preparation of activated carbon from bituminous coal with phosphoric acid activation. Carbon 1998; 36(9): 1387-1395.

[43] Suárez-García F, Martínez-Alonso A, Tascón JMD. Activated carbon fibers from Nomex by chemical activation with phosphoric acid. Carbon 2004; 42(8-9): 1419-1426.

[44] Lillo-Ródenas MA, Cazorla-Amorós D, Linares-Solano A. Understanding chemical reactions between carbons and $\mathrm{NaOH}$ and $\mathrm{KOH}$ : An insight into the chemical activation mechanism. Carbon 2003; 41(2): 267-275.

[45] Lillo-Ródenas MA, Juan-Juan J, Cazorla-Amorós D, Linares-Solano A. About reactions occurring during chemical activation with hydroxides. Carbon 2004; 42(7): 1371-1375.

[46] Marsh H, Yan DS, O'Grady TM, Wennerberg A. Formation of active carbons from cokes using potassium hydroxide. Carbon 1984; 22(6): 603-611.

[47] Lozano-Castelló D, Lillo-Ródenas MA, Cazorla-Amorós D, Linares-Solano A. Preparation of activated carbons from Spanish anthracite: I. Activation by KOH. Carbon 2001; 39(5): 741-749. 
[48] Yoon SH, Lim S, Song Y, Ota Y, Qiao W, Tanaka A, Mochida I. KOH activation of carbon nanofibers. Carbon 2004; 42(8-9): 1723-1729.

[49] Joncourt L, Mermoux M, Touzain PH, Bonnetain L, Dumas D, Allard B. Sodium reactivity with carbons. J Phys Chem Solids 1996; 57(6-8): 877-882.

[50] Raymundo-Piñero E, Azaïs P, Cacciaguerra T, Cazorla-Amorós D, Linares-Solano A, Béguin F. $\mathrm{KOH}$ and $\mathrm{NaOH}$ activation mechanisms of multiwalled carbon nanotubes with different structural organization. Carbon 2005; 43(4): 786-795.

[51] Endo M, Furuta T, Minoura F, Kim C, Oshida K, Dresselhaus G, Dresselhaus MS. Visualized observation of pores in activated carbon fibers by HRTEM and combined image processor. Supramolecular Sci 1998; 5(3-4): 261-266.

[52] Harris PJF, Liu Z, Suenaga K. Imaging the atomic structure of activated carbon. J Phys: Condens Matter 2008; 20(36): 362201-362205.

[53] Wang H, Gao Q, Hu J. High hydrogen storage capacity of porous carbons prepared by using activated carbon. J Am Chem Soc 2009; 131(20): 7016-7022.

[54] Tang Z, Shen S, Zhuang J, and Wang X. Noble-metal-promoted three-dimensional macroassembly of single-layered graphene oxide. Angew Chem Int Ed 2010; 122(27): 4707-4711.

[55] Estevez L, Kelarakis A, Gong Q, Da'as EH, Giannelis EP. Multifunctional graphene/platinum/nafion hybrids via ice templating. J Am Chem Soc 2011, 133 (16): $6122-6125$.

[56] Li J, Wang X, Huang Q, Gamboa S, Sebastian PJ. Studies on preparation and performances of carbon aerogel electrodes for the application of supercapacitor. J Power 
Sources 2006, 158 (1): 784-788.

[57] He Y, Chen W, Li X, Zhang Z, Fu J, Zhao C, et al. Freestanding three-dimensional graphene/ $\mathrm{MnO}_{2}$ composite networks as ultralight and flexible supercapacitor electrodes. ACSNano 2013, 7(1): 174-182.

[58] Zhang F, Tang J, Wang Z, Qin LC. Graphene-carbon nanotube composite aerogel for selective detection of uric acid. Chem Phys Lett 2013, 590: 121-125.

[59] Gosalawit-Utke RG, Nielsen TK, Pranzas K, Saldan I, Pistidda C, Karimi F, et al. $2 \mathrm{LiBH}_{4}-\mathrm{MgH}_{2}$ in a resorcinol furfural carbon aerogel ccaffold for reversible hydrogen storage. J Phys Chem C 2012, 116(1): 1526-1534.

[60] Bi H, Yin Z, Cao X, Xie X, Tan C, Huang X, et al. Carbon fiber aerogel made from raw cotton: A Novel, efficient and recyclable sorbent for oils and organic solvents. Adv Mater 2013, 25(41): 5916-5921.

[61] Ohba T, Takase A, Ohyama Y, Kanoh H. Grand canonical Monte Carlo simulations of nitrogen adsorption on graphene materials with varying layer number. Carbon 2013; 61: 40-46.

[62] Guo F, Creighton M, Chen Y, Hurt R, Külaots I. Porous structures in stacked, crumpled and pillared graphene-based 3D materials. Carbon 2014; 66: 476-484. 